
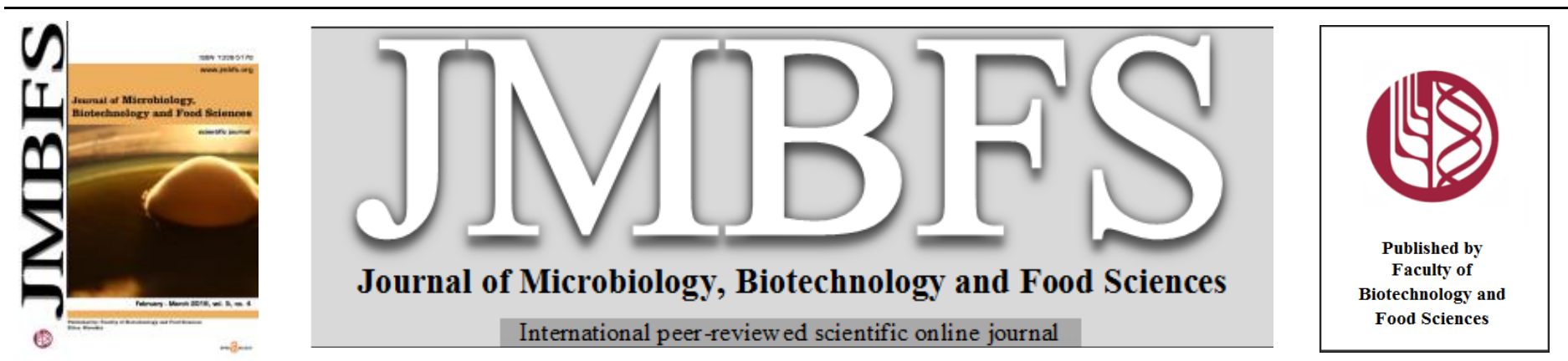

\title{
FUNGAL CONTAMINATION AND MYCOTOXIN PRODUCTION BY ASPERGILLUS SPP. IN NUTS AND SESAME SEEDS
}

\section{Nouara Aït Mimoune ${ }^{1,2}$, Amar Riba ${ }^{1,2}$, Carol Verheecke ${ }^{3}$, Florence Mathieu ${ }^{3}$ and Nasserdine Sabaou ${ }^{2}$}

Address(es): Nouara Aït Mimoune,

${ }^{1}$ Laboratoire de Biologie des Systèmes Microbiens (LBSM), Ecole Normale Supérieure de Kouba, Alger, Algeria.

${ }^{2}$ Département de Biologie, Faculté des Sciences, Université M’hamed Bougara, Boumerdès, Algeria.

${ }^{3}$ Université de Toulouse, INPT-ENSAT, Laboratoire de Génie Chimique, UMR 5503 (CNRS/INPT/UPS), 1 Avenue de l'Agrobiopôle BP 32607 Auzeville Tolosane

31326 Castanet-Tolosan, France.

*Corresponding author: nouara@ @live.fr

doi: 10.15414/jmbfs.2016.5.4.301-305

\section{ARTICLE INFO}

Received 1. 12. 2014

Revised 14. 1. 2015

Accepted 21. 10. 2015

Published 1. 2. 2016

Regular article

open 2 access

\begin{abstract}
This work reports the occurrence of the fungal flora and evaluates the mycotoxigenic potential of Aspergillus genera in 63 samples of oil seeds and nuts (almonds, pistachio and sesame seeds). Fungal isolation and identification revealed the presence of 5 genera (Aspergillus, Penicillium, Cladosporium, Mucor and yeasts) with the predominance of Aspergillus section Nigri. A number of 138 strains of Aspergillus section Nigri and 91 of Aspergillus section Flavi were isolated and tested for their ability to produce ochratoxin A (OTA) and Aflatoxin, respectively. The detection of Aflatoxins and OTA production was carried out using thin-layer chromatography (TLC). Our results showed that $93.93 \%$ of Aspergillus carbonarius were able to produce OTA, but none of the Aspergillus niger aggregate was found to be an OTA-producer. Among the 91 Aspergillus section Flavi isolates, 88 were identified as Aspergillus flavus and 3 as Aspergillus parasiticus. All A. parasiticus were strong AFB and AFG producers. A percentage of $30.3 \%$ of A. flavus isolates produced AFB1, with levels ranging from 0.69 to $44.28 \mu \mathrm{g} . \mathrm{g}^{-1}$. The frequency of aflatoxigenic A. flavus strains was higher in pistachios (46.3\%) than in almonds $(30.3 \%)$ or sesame seeds $(23.52 \%)$. Cyclopiazonic acid (CPA) and sclerotia production were carried out on CYA medium. All aflatoxigenic A. flavus strains produced CPA, whereas 29.2\% produced sclerotia (L-type).
\end{abstract}

Keywords: Aspergillus, aflatoxin, ochratoxin A, cyclopiazonic acid, sclerotia

\section{INTRODUCTION}

Mycotoxins are toxic secondary metabolites produced primarily by Aspergillus, Penicillium and Fusarium spp. under appropriate environmental conditions. They are considered to be a major factor in the spoilage of foodstuffs, leading to great economic loss and a major public health hazard (Dwivedi $\boldsymbol{e t}$ al., 1984). Human exposure to mycotoxins is difficult to avoid because Aspergillus grows aggressively in many commodities and at all stages of the food chain: in the field and during storage or processing (DeVries et al., 2002). Aflatoxins and ochratoxin A are toxins of serious concern witch are synthesized by several Aspergillus species and are highly toxic to humans and animals. AFs are synthesized by species of Aspergillus section Flavi and especially by A. flavus and $A$. parasiticus. The most common and toxic aflatoxins (AFs) naturally occurring are AFB1, B2, G1 and G2 (Astoreca et al, 2011). They have been clearly identified as highly toxic, mutagenic, teratogenic, and carcinogenic compounds and have been implicated as causative agents in human hepatic and extrahepatic carcinogenesis (Massey et al., 1995). The International Agency for Research on Cancer has classified naturally occurring mixtures of aflatoxins as carcinogenic to humans (Group 1) (IARC 2002). Many foods and feeds can become contaminated with aflatoxin; however, the most pronounced aflatoxin contamination is in cereals, nuts, cotton, fig, spice and coffee (Freitas and Brigido, 1998). Ochratoxin A is a nephrotoxic mycotoxin produced by several species of the genera Aspergillus and Penicillium. The occurrence of ochratoxin A on food commodities such as grapes or grape products, spices, coffee and cocoa is mainly due to the presence of $A$. ochraceus, $A$. carbonarius and A. niger (Schmidt-Heydt et al., 2011). The co-occurrence of different mycotoxins increases the probability of synergistic effects, which can increase the risk to human health. In addition to AF, some A. flavus strains produce other mycotoxins such as cyclopiazonic acid (CPA). CPA is an indole tetramic acid that is toxic to animals and humans. CPA-producing fungi can grow on many substrates, including cheese, meat products, and various grains and seeds (Chang et al, 2009). Co-contamination of food commodities by CPA and carcinogenic aflatoxins has been reported in different geographic areas (Horn and Dorner,
1999; Martins and Martins, 1999; Fernandez-Pinto et al., 2001). The toxicity of CPA in many animal species has been studied. It causes weight loss, diarrhea, degeneration and necrosis of the muscles and viscera, convulsion and death (Purchase, 1971; Dorner et al., 1983; Nuehring et al., 1985). The aim of the present work is the study of fungal contamination and mycotoxins (aflatoxins, ochratoxin A and CPA) production by Aspergillus strains isolated from several samples of stored oilseeds in Algeria to provide useful information.

\section{MATERIAL AND METHODS}

\section{Sampling}

A total of 63 samples were investigated in this study. Samples were randomly collected between (April-July) 2011 from different markets and shops in north Algeria (sample sizes of $200 \mathrm{~g}$ ). The selected commodity groups were: pistachio (15 samples), almonds (36 samples) and sesame seeds (12 samples). Samples were stored in plastic bags at $4^{\circ} \mathrm{C}$ until the analysis.

\section{Reagents}

All reagents (potassium chloride, phosphoric acid, hydrochloric acid, ammonium hydroxide, $\beta$-cyclodextrin) were of PA grade. Deionized water was used for the preparation of all aqueous solutions. Mycotoxin standards (aflatoxins, ochratoxin $A$ and cyclopiazonic acid) and Ehrlich's reagent (4-dimethylaminobenzaldehyde) were purchased from Sigma Aldrich (France). All other solvents and reagents were of analytical grade purchased from Merck, Germany.

\section{Fungal isolation and identification}

Dilution plating was used as the enumeration technique (Pitt and Hocking, 1997). Ten grams of each grounded sample were dispersed in $90 \mathrm{~mL}$ of $0.05 \%$ Tween 80 sterile distilled water. Decimal dilutions (up to $10^{-3}$ ) were prepared and $0.1 \mathrm{~mL}$ of each dilution was inoculated in duplicate on DRBC (Dichloran Rose- 
Bengal Chloramphenicol Agar) medium. All plates were incubated for 5 days at $28^{\circ} \mathrm{C}$. The concentrations of fungi were expressed as colony forming units per $\mathrm{g}$ (CFU/g). After incubation species belonging to the genera of Aspergillus were isolated and identified. For morphological identification, isolated species were sub-cultured on three media: Czapek Yeast Agar (CYA), Aspergillus flavus and parasiticus agar (AFAP) and Czapek agar (CZ). Identification was performed according to standard taxonomic systems based on color of colony, the shape of conidiophores and conidia's dimension examined microscopically (Pitt and Hocking, 1997; Klich, 2002). Identification of Aspergillus section Flavi was completed by taking into account a combination of all the observed criteria, including, sclerotial production and AFs and CPA profiles.

\section{Aflatoxigenic ability of the isolates}

Aspergillus section Flavi isolates were maintained on plates containing Coconut agar medium (CAM) (Davis et al., 1987). On this medium, aflatoxin-positive isolates showed a blue or blue-green fluorescence in agar surrounding the colonies under UV light. Inoculations were done by conidial transfer to center of plates containing (CAM). The plates were incubated at $28{ }^{\circ} \mathrm{C}$ in the dark for 7 days. The reverse side of colonies was periodically observed under long-wave (365 nm) UV light. Cultures were examined daily (for 1 week) under the UV light for detection of florescence signal of aflatoxigenic isolates. A blank consisting of sterilized, non-inoculated CAM medium, incubated under the same conditions, was used as control. To confirm the correlation between fluorescence and aflatoxin production, all colonies, whether or not they showed fluorescence were extracted according to the method described by (Filtenborg et al., 1983) The agar plug methods for extracellular and intracellular mycotoxins were used for toxin extraction of the colonies. Three agar plugs of the solid medium were removed from different points of the colony for each culture, weighted and collected into small tubes. Extraction was done by adding a volume of $1 \mathrm{~mL}$ of methanol to each tube (Bragulatet al., 2001). After incubation for 1 hour at room temperature, all tubes were centrifuged at $13000 \mathrm{rpm}$ for $10 \mathrm{~min}$. The obtained extracts were filtered through a $0.45 \mu \mathrm{m}$ Millipore filter then analyzed by TLC. Quantification of aflatoxin B was done by HPLC.

\section{CPA production}

The strains were tested for cyclopiazonic acid in Czapek Yeast Agar medium (CYA: Sucrose $30 \mathrm{~g} / \mathrm{L}$, Powdered Yeast Extract $5 \mathrm{~g} / \mathrm{L}, \mathrm{K}_{2} \mathrm{HPO}_{4} 1 \mathrm{~g} / \mathrm{L}, \mathrm{NaNO}_{3} 2$ $\mathrm{g} / \mathrm{L}, \mathrm{KCl} 0.5 \mathrm{~g} / \mathrm{L}, \mathrm{MgSO}_{4} \cdot 7 \mathrm{H}_{2} \mathrm{O} 0.5 \mathrm{~g} / \mathrm{L}, \mathrm{FeSO} 4 \cdot 7 \mathrm{H}_{2} \mathrm{O} 0.01 \mathrm{~g} / \mathrm{L}, \mathrm{ZnSO}_{4} \cdot 7 \mathrm{H}_{2} \mathrm{O}$ $0.01 \mathrm{~g} / \mathrm{L}, \mathrm{CuSO}_{4} \cdot 5 \mathrm{H}_{2} \mathrm{O} 0.005 \mathrm{~g} / \mathrm{L}$, Agar $20 \mathrm{~g} / \mathrm{L}$ ). All strains were inoculated on 6 $\mathrm{cm}$ diameter plates and incubated at $28{ }^{\circ} \mathrm{C}$ for 14 days, in the dark (Gqaleni $\boldsymbol{e}$ al., 1997). The experiment was carried out with two replicates. Following incubation, the methodology of Bragulat et al. (2001) described previously was employed. The obtained extracts were analyzed using thin-layer chromatography (TLC).

\section{Detection of aflatoxins and CPA production by TLC}

The analysis of aflatoxins and CPA production of all Aspergillus section Flavi was carried out on a silica gel 60 plate $20 \times 20 \mathrm{~cm}$ (Merck). For aflatoxins, chloroform: acetone (90:10, v/v) was used as developing solvent. $20 \mu \mathrm{L}$ of 1 $\mu \mathrm{g} . \mathrm{mL}^{-1}$ concentration of B1, B2, G1 and G2 aflatoxins and $20 \mu \mathrm{L}$ of test samples were spotted on TLC plates and run for $45 \mathrm{~min}$ in a TLC tank. Plates were air dried and observed under UV light $(365 \mathrm{~nm})$ for presence or absence of fluorescent spots as well as their intensity. The detection of CPA was performed using Ethyl acetate/propanol/ammonium hydroxide (40:30:20) as developing solvent system (Fernandez Pinto et al., 2001). The plates were dipped first in a $2 \%$ solution of oxalic acid in methanol for $2 \mathrm{~min} .20 \mu \mathrm{L}$ of test samples and CPA standard were spotted on TLC plates. After plates development CPA was visualized in daylight by treatment of the plates with Ehrlich's Reagent ( $1 \mathrm{~g}$ of 4 dimethyl amino benzaldehyde in $75 \mathrm{~mL}$ ethanol and $25 \mathrm{~mL}$ concentrated $\mathrm{HCl}$ ) and appeared as a blue-purple spot.

\section{HPLC analysis of AFB}

The quantitative determination of AFB produced by aflatoxigenic isolates of Aspergillus flavus was performed with HPLC. The HPLC apparatus was a Shimadzu Liquid Chromatograph AD-0012-LC equipped with a Post-column Bromination (Coring Cell) and a fluorescence detector (365 nm excitation wavelength; $435 \mathrm{~nm}$ emission wavelength), Chromatographic separations were performed on a reverse phase C18 column ( $250 \times 4 \mathrm{~mm}, 3 \mu \mathrm{m}$ particle size $)$. The system was run using a mobile phase containing distilled water, acetonitrile, methanol $(6: 2: 2, \mathrm{v} / \mathrm{v} / \mathrm{v})$ with $119 \mathrm{mg} / \mathrm{L}$ of $\mathrm{KBr}$ and $110 \mu \mathrm{L} / \mathrm{L}$ of $65 \% \mathrm{HNO}_{3}$ under isocratic elution with a flow rate of $1 \mathrm{~mL} / \mathrm{min}$. The injection volume was $20 \mu \mathrm{L}$.

\section{Sclerotial characterization}

To assay for sclerotia production, plates containing CYA medium were inoculated with Aspergillus section Flavi mycelia obtained from a culture of 7 days in Potato dextrose agar medium (PDA). Cultures were incubated in darkness for 21 days at $30^{\circ} \mathrm{C}$. Sclerotia were obtained by pouring $10 \mathrm{~mL}$ of water with Tween $80(0.01 \%)$ per plate and scraping the surface of culture plates (two replicate plates per isolate) over Whatman filter paper and rinsing with tap water to finally air-dried (Novas and Cabral, 2002). Formation of sclerotia was confirmed visually and selerotia type of each culture was confirmed by measuring their size. The sclerotia isolates were classified according to the sclerotia size; L strain isolates produced very few sclerotia with diameter greater than $400 \mu \mathrm{m}$, and $\mathrm{S}$ strain isolates produced numerous sclerotia with diameter under $400 \mu \mathrm{m}$ (Cotty, 1989).

\section{Ochratoxin A production and analysis}

The production of OTA was studied on 105 strains of Aspergillus niger aggregate and 33 of A. carbonarius. All isolates were cultured on CYA medium for 7 days at $28^{\circ} \mathrm{C}$. OTA was extracted by the agar plug method (previously described). OTA production was detected in the extracts by thin layer chromatography (TLC) using toluene/ethyl acetate/ $90 \%$ formic acid (5:4:1, v/v/v) as developing solvent.

\section{RESULTS}

\section{Fungal contamination}

Significant differences were observed between the frequency of fungal isolates in almonds, pistachio and sesame seeds. Almonds were the most contaminated raw material $\left(8.05 \times 10^{3} \mathrm{CFU} / \mathrm{g}\right)$ followed by pistachios $\left(6.85 \times 10^{3} \mathrm{CFU} / \mathrm{g}\right)$ and sesame seeds $\left(2.95 \times 10^{3} \mathrm{CFU} / \mathrm{g}\right)$. Mycological analysis showed that all samples were contaminated by fungi, excepted salted almonds ( 8 samples). Five genera were isolated from different nuts and sesame seeds. The frequencies of isolated fung from different nuts were Aspergillus (84.69\%), Penicillium (9.31\%), Mucor $(4.48 \%)$, Cladosporium $(0.84 \%)$ and yeasts $(0.68 \%)$. Aspergillus was the most common genus of fungi and was represented by species including: A. flavus, $A$ parasiticus, A. niger aggregate, A. carbonarius and A. ochraceus. Predominant mycobiota belonged to the genera Aspergillus section Nigri and were represented by $A$. carbonarius and $A$. niger aggregate (Tab 1 ). These two species were differentiated by their conidia size. A. niger aggregate and A. flavus were found in $76.66 \%$ and $53.33 \%$ of samples, respectively, Aspergillus niger aggregate was the most dominant.

Table 1 Abundance and distribution of Aspergillus isolates in the different samples

\begin{tabular}{lcccc}
\hline Sample & Almond & $\begin{array}{c}\text { Sesame } \\
\text { seeds }\end{array}$ & Pistachio & $\begin{array}{c}\text { Isolates } \\
\text { tested }\end{array}$ \\
\hline A. flavus & $5.7 \%$ & $6.37 \%$ & $25.03 \%$ & 88 \\
\hline A. parasiticus & $0.81 \%$ & $0.63 \%$ & $1.21 \%$ & 3 \\
\hline $\begin{array}{l}\text { A. niger } \\
\text { aggregate }\end{array}$ & $76.71 \%$ & $46.08 \%$ & $72.89 \%$ & 105 \\
\hline A. carbonarius & $2.54 \%$ & $17.85 \%$ & - & 33 \\
\hline A. ochraceus & - & $0.8 \%$ & - & - \\
\hline
\end{tabular}

\section{Aspergillus section Flavi identification}

Aspergillus section Flavi isolates were identified using morphological characters (mainly colony color on CZ, CYA and conidia morphology) by comparison to reference strains of $A$. flavus, A. parasiticus and A. nomius. Ninety one isolates belonging to Aspergillus section Flavi were obtained exclusively from almonds (33), pistachio (41) and sesame seeds (17). Aspergillus strains were classified in two groups: isolates with dark-green colonies and rough conidia, which were classified as A. parasiticus (3 isolates), and isolates with yellow-green colonies and smooth to finely rough globose conidia, classified as A. flavus ( 88 isolates). A. flavus (producing aflatoxin B) and A. parasiticus (producing aflatoxins B and $G)$ were found together on all samples and they showed a bright orange color of the colony reverse on AFPA.

\section{Analysis of aflatoxins}

Among the 91 isolates of Aspergillus section Flavi tested for aflatoxins production on CAM, 26 isolates $(28.59 \%)$ showed fluorescence in this medium after 5-7 days of incubation. These results were in concordance with those obtained from the methanol extracts from all strains cultivated in CA medium. Aflatoxins production led to the development of fluorescent area around the colonies under UV light. None of the fluorescent isolates were found to be unable to produce aflatoxins under the same conditions. TLC analysis of the extracts showed that, 33 isolates $(36.26 \%)$ were aflatoxin producers. Thirty isolates were identified previously as A. flavus produced only aflatoxin B, while A. parasiticus isolates ( 3 isolates) were aflatoxinogenic and were capable to produce both aflatoxins B1 and G1. All strains producing a strong blue fluorescence on CAM after 5 days of incubation showed a high AFBs production whereas those with a weak fluorescence on CAM, detectable after 7 days of incubation were weak 
producers. The quantitative analysis of aflatoxin by HPLC showed concentrations of AFB1 ranging between $0.69 \mu \mathrm{g} . \mathrm{g}^{-1}$ to $44.28 \mu \mathrm{g} . \mathrm{g}^{-1}$ and lower levels of AFB2 ranging from $0.2 \mu \mathrm{g} . \mathrm{g}^{-1}$ to $6.05 \mu \mathrm{g} \cdot \mathrm{g}^{-1}$ (Tab 2).

Table 2 Aflatoxin-producing ability of isolated Aspergillus section Flavi strains.

\begin{tabular}{lccc}
\hline Species & $\begin{array}{c}\text { Total strains } \\
(\boldsymbol{\%})\end{array}$ & $\begin{array}{c}\text { AFB1 }(\boldsymbol{\mu g} / \mathbf{g}) \\
\text { Positive strains } \\
(\boldsymbol{\%})\end{array}$ & $\begin{array}{c}\text { AFB2 }(\boldsymbol{\mu g} / \mathbf{g}) \\
\text { Positive strains } \\
(\boldsymbol{\%})\end{array}$ \\
\hline A. flavus & $88(96.7)$ & $0.69-44.28(34.09)$ & $0.2-6.05(30.68)$ \\
\hline A. parasiticus & $3(3.3)$ & $53.2-54.35(100)$ & $2.14-3.98(100)$ \\
\hline
\end{tabular}

\section{Sclerotial and CPA production}

The sclerotia had a nearly spherical shape with irregular margins, strongly dense and hard, at first creamy white in color and blackish gray over time. Fifteen strains (16.48\% of total strains) were able to produce only large sclerotia (L). $24.24 \%$ ( 8 isolates) of aflatoxigenic A. flavus isolates were found to be sclerotia producers. All aflatoxigenic isolates produced also CPA. However, A. parasiticus strains were strong AFB and AFG producers, but did not produce detectable CPA and sclerotia.

\section{Identification of chemotypes}

The strains were classified into chemotypes based on AFs and CPA production patterns (Tab 3). Atoxigenic isolates were the most represented chemotype $(65.9 \%)$. No strains were found able to produce AFB, AFG and CPA. $34.09 \%$ of A. flavus produced $\mathrm{AFB}$ and $\mathrm{CPA}$ and were included in a different chemotypes. A. parasiticus isolates produced both $\mathrm{AFB}$ and $\mathrm{AFG}$ but were not able to produce CPA.

Table 3 Incidence of chemotypes of Aspergillus section Flavi based on mycotoxigenic profile (AFs and CPA) (Vaamonde et al., 2003).

\begin{tabular}{lcccc}
\hline Chemotype & \multicolumn{3}{c}{ Mycotoxins } & $\begin{array}{c}\text { Number of } \\
\text { isolates of each } \\
\text { chemotype (\%) }\end{array}$ \\
\cline { 2 - 5 } & AFB & AFG & CPA & $30(32.96 \%)$ \\
\hline I & + & - & + & 0 \\
\hline II & + & + & + & $3(3.29 \%)$ \\
\hline IV & + & + & - & 0 \\
\hline V & - & - & + & $58(63.73 \%)$ \\
\hline L & - & - & - &
\end{tabular}

Legend: (+) - presence, (-) - absence.

\section{Ochratoxin A production}

The ochratoxiginity of $A$. carbonarius and Aspergillus niger aggregate strains from the methanolic extracts was determined by TLC. Our results showed a high production percentage within A. carbonarius isolates, indeed, $93.93 \%$ isolates out of 33 ) were able to produce OTA. In the other side all strains that belong to A. niger aggregate (105 isolates) were found to be non-producers of OTA.

\section{DISCUSSION}

Food products may become contaminated by fungi that can be responsible of damaging them. Contamination of edible greasy seeds by fungi, mostly pistachio and almond, were reported in different countries. Fungal identification is very important to provide information about which mycotoxins could be present (Maenetje and Dutton, 2007). To date, a small research has been done in this area in Algeria. This work had been performed to investigate the contamination of some oilseeds. Total fungal counts showed a good quality of the studied food products with acceptable contamination levels ranged from $2.95 \times 10^{3}$ to $8.05 \times 10^{3}$ CFU/g (Andrews, 1992). The assessment of the incidence of fungal flora revealed that $(80 \%)$ of grain samples contained more than one species of fungi. Aspergilli were the major species most commonly isolated in all products. The incidence of Aspergillus section Nigri was higher than those belonging to Aspergillus section Flavi. This species is a very frequent fungal contaminant found worldwide on various substrates such as cereals, grapes, coffee bean and nuts. Fungal and mycotoxins contaminations vary depending on the climate. In Algeria, climatic conditions characterized by high humidity and temperature and inadequate storage practices contribute to increase the potential for contamination of the commodities by Aspergillus and their toxins (Riba et al., 2010). Aspergillus and Penicillium species mainly grow during storage. The predominance of Aspergillus in stored nuts bean has been reported by several authors (Adebajo and Diyaolu, 2003; Rostami et al., 2009). Salted almonds (8 samples) instead, did not show any fungal contamination. This can be explained by the strong activity of salt against fungal growth. Similar results were obtained by other workers including Thamaboripat $\boldsymbol{e t}$ al. (1992); they reported that high concentrations of $\mathrm{NaCl}$ may affect the water activity required for fungal growth. From all the analyzed samples 91 strains of Aspergillus section Flavi were tested for their ability to produce aflatoxins on Coconut Agar Medium (CAM). The presence of fluorescence on this medium was correlated with AFs production at a very high level on TLC and HPLC.

On the basis of sclerotial size A. flavus isolates can be divided into two subtypes (L-type and S-type). Many studies attempt to found a relationship between aflatoxins production and sclerotial phenotype. Some showed a positive interrelationship between regulation of aflatoxin biosynthesis and the production of small sclerotia (Novas and Cabral, 2002; Pildain et al., 2004). Whereas, others observed that the L strains produce higher levels of aflatoxins than the $\mathrm{S}$ strain isolates (Astoreca et al., 2011; Abbas et al., 2005). In our survey, sclerotia were all of the L-type $(>400 \mu \mathrm{m})$, and were present in $29.2 \%$ of the $A$ flavus isolates. Small sclerotia production was not found. No correlation could be established between sclerotia presence/size and toxigenicity in this case Abundance of L strains was reported in many previous studies (Astoreca $\boldsymbol{e t}$ al., 2011; Donner et al., 2009; Giorni et al., 2007). The conditions responsible for the distribution of $A$. flavus S- strains still unknown and appear to be complex. Environmental factors are known to affect sclerotial biogenesis. For example, in the Eastern Province of Kenya the domination of S-strains was observed (Probst et al., 2007; Pildain et al., 2008). Recently, Riba et al. (2010) reported a dominance of L-strains in Algerian wheat simples. These results contrast with those reported in our investigation, showing a positive correlation between the distribution of these two different types and the environment factors.

The mycotoxigenic potential and profile of A. flavus is known to be variable This species has been frequently divided into groups, depending on their toxigenic profile (Razzaghi-Abyaneh et al., 2006; Vaamonde et al., 2003). In our work, more than half isolates $(65.9 \%)$ are atoxigenic. Analogous results were reported in many studies by several authors showing a high percentage of these isolates in various foodstuffs (Horn and Dorner, 1999; Razzaghi-Abyaneh $\boldsymbol{e}$ al., 2006; Sanchez-Hervas et al., 2008). In general, the incidence of atoxigenic strains of Aspergillus section Flavi communities varies with geographic origin (Atehnkeng et al., 2008; Pildain et al., 2004) and substrate (Vaamonde et al., 2003). In the present study, A. flavus isolated from Pistachio showed a high aflatoxins production $(46.3 \%)$, than those isolated from almonds $(30.3 \%)$ and sesame seeds (23.52\%). Atypical A. flavus isolates (Group II), which produce small sclerotia and AFB, AFG and CPA have not been identified in our survey. This kind of isolates is intermediate between A. flavus and $A$ parasiticus. This phenotype has been previously isolated in soil and agricultural samples from West Africa, Argentina and Australia and has been classified as $A$ minisclerotigenes (Pildainet al., 2008). 30 strains (34.09\%) of A. flavus were capable to produce both CPA and AFB (chemotype III). This type of isolates belongs to typical A. flavus isolates. The co-occurrence of aflatoxins with cyclopiazonic acid has been reported in peanuts, corn and animal feeds in different geographic areas (Uranoet al., 1992; Horn and Dorner, 1999; Martins and Martins, 1999; Fernandez-Pinto et al., 2001). A. parasiticus strains are more uniformin their toxigenic abilities: they are usually reported as strongly aflatoxigenic (Horn et al., 1996; Razzaghi-Abyanehet al., 2006; TranDinhet al., 1999). They are also known to be producers of B- and G-type aflatoxins but never CPA. All A. parasiticus isolates were found to be strongly aflatoxigenic and produce both AFB and G.

Black aspergilli were tested on CYA medium for ochratoxin A production. None of $A$. niger aggregate produced ochratoxin $\mathrm{A}$, but 31 of 33 isolates of $A$. carbonarius were able to produce this toxin. Among the species belonging to the Aspergillus genera (A. niger, A. ochraceus and A. carbonarius) A. carbonarius is the main OTA-producers. Strains of $A$. niger are considered as weak OTAproducers (El Khoury and Atoui, 2010). Battilani et al. (2003) found that the most ochratoxigenic strains isolated from grapes belonged to A. carbonarius Also, this species is the most probable source of OTA in dried vine fruits (Abarcaet al. 2003). Our findings are in agreement with most other studies on these species. Battilani et al. (2006) and Perrone et al. (2006) reported high percentage of OTA producers on A. carbonarius (from 70-100\%), although, $A$. niger aggregate, the most common, showed a low percentage $(20 \%)$ of OTA producing strains.

\section{CONCLUSION}

This research has provided information about contamination by molds and their mycotoxins in some Algerian greasy edible seeds. A very high development of Aspergillus genus has been noted. A study of the aflatoxigenicity of 91 Aspergillus section Flavi isolated and identified by a combination of morphological criteria, and mycotoxin profiles, revealed that all A. parasiticus strains were aflatoxigenic and produce both AFB and AFG, whereas $30.3 \%$ of $A$ flavus isolates produced only AFB. The aflatoxigenicity of these isolates was variable in all samples. In almonds and sesame seeds a development of $A$ carbonarius has been observed. This species was found to be highly ochratoxigenic. The presence of species like A. flavus, A. parasiticus and $A$ carbonarius, can lead to aflatoxins and OTA production in foodstuffs. To minimize fungi contamination and manage the risk of mycotoxins production, good storage practices and control measures should be established because it still the most effective tool to use. 


\section{REFERENCES}

ABBAS, HK., WEAVER, MA., ZABLOTOWICZ, RM., HORN, BW., SHIER WT. 2005. Relationships between aflatoxin production and sclerotia formation among isolates of Aspergillus Section Flavi from the Mississippi Delta.European Journal of Plant Pathology, 112 (3), 283-287. http://dx.doi.org/10.1007/s10658 $\underline{004-4888-8}$

ABARCA, ML., ACCENSI, F., BRAGUlAT, MR., CASTELlA', G., CABANES, FJ. 2003. A. carbonarius as the main source of OTA contamination in dried vine fruits from Spanish market. Journal of Food Protection, 66 (1), 504506

ADEBAJO, L.O., DIYAOLU, S.A. 2003.Mycology and spoilage of retail cashew nuts.African Journal of Biotechnology,2 373.http://dx.doi.org/10.5897/AJB2003.000-1076

ANDREWS, S. 1992. Specifications for fungi in Australian foods. In: Samson, R. A., Hocking, A.D., Pitt, J. I. and King, A.D. (Eds.), Modern Methods in Food Mycology, Elsevier, Amsterdam, p. 97-110.

ASTORECA, A.L., DALCERO, A.M., FERNÁNDEZ-PINTO, V. VAAMONDE, G. 2011. A survey on distribution and toxigenicity of Aspergillus section Flavi in poultry feeds. International Journal of Food Microbiology, 146 (1), 38-43.http :// dx.doi. org/10.1016/j.ijfood m icro .2011.01.034

ATEHNKENG, J., OJIAMBO, PS., DONNER, M., IKOTUN, T., SIKORA, RA. COTTY, PJ., BANDYOPADHYAY, R. 2008. Distribution and toxigenicity of Aspergillus species isolated from maize kernels from three agro-ecological zones in Nigeria. International Journal of Food Microbiology, 122 (1), 74-84.

http://dx.doi.org/10.1016/j.ijfoodmicro.2007.11.062

BATTILANI, P., PIETRI, A., BERTUZZI, T., LANGUASCO, L., GIORNI, P KOZAKIEWICZ, Z. 2003. Occurrence of ochratoxin A-producing fungi in grapes grown in Italy.Journal of Food Protection,66 (4), 633-636.

BATTILANI, P., BARBANO, C., MARIN, S., SANCHIS, V., KOZAKIEWICZ Z., MAGAN, N. 2006. Mapping of Aspergillus Section Nigri in Southern Europe and Israel based on geostatistical analysis. International Journal of Food Microbiology,

111(1)

S72-S82.

http://dx.doi.org/10.1016/j.ijfoodmicro.2006.03.014

BRAGULAT, M.R., ABARCA, M.L., CABAÑES, F.J. 2001.An easy screening method for fungi producing ochratoxinA in pure culture.International Journal of Food Microbiology, 71(2), 139-144. http://dx.doi.org/10.1016/S0168 1605(01)00581-5

CHANG, P.K., HORN, B.W., DORNER, J.W. 2009. Clustered genes involved in cyclopiazonic acid production are next to the aflatoxin biosynthesis gene cluste in Aspergillus flavus. Fungal Genetics and Biology, 46(2), http://dx.doi.org/176 182. 10.1016/j.fgb.2008.11.002

COTTY, P. J. 1989.Virulence and cultural characteristics of two Aspergillus flavus strains pathogenic on cotton.Phytopathology, 79 (7), 808-814 http://ag.arizona.edu/research/cottylab/apdfs/Phytopathology\%2079 808-814.pdf DAVIS, N.D., IYER, S.K., DIENER, U.L. 1987.Improved method of screening for aflatoxin with a coconut agar medium.Applied and Environmental Microbiology, 53(7), $1593-1595$

http://www.ncbi.nlm.nih.gov/pmc/articles/PMC203916/

DEVRIES, J.W., TRUCKESS, M.W., JACKSON, L.S. 2002. Mycotoxins and food safety.2003.

DONNER, M., ATEHNKENG, J., SIKORA, RA., BANDYOPADHYAY, R COTTY, PJ. 2009. Distribution of Aspergillus section Flavi in soils of maize fields in three agroecological zones of Nigeria. Soil Biology and Biochemistry, 41(1), 37-44.

DORNER, JW., COLE, RJ., LOMAX, LG., GOSSER, HS., DIENER, UL. 1983 Cyclopiazonic acid production by Aspergillus flavus and its effects on broile chickens. Applied and Environmental Microbiology, 46(6), 698-703.

DWIVEDI, P., BURNS, R.B. 1984. Effect of ochratoxin A on immunoglobulins in broiler chickens. Research in Veterinary Science, 36 (1), 117-121.

EL KHOURY, A., ATOUI, A. 2010. Ochratoxin A: general overview and actual molecular status. Toxins, 2 (4), 461-493. http://dx.doi.org /10.339/toxins 2040461

FERNANDEZ PINTO, V., PATRIARCA, A., LOCANI, O., VAAMONDE, G. 2001. Natural cooccurrence of aflatoxin and cyclopiazonic acid in peanuts grown in Argentina.Food Additives and Contaminants, 18(11), 1017-1020. http://dx.doi.org/10.1080/ 02652030110057125

FILTENBORG, O., FRISVAD, JC., SVENDSEN, JA. 1983. Simple screening method for molds producing intracellular mycotoxins in pure cultures. Applied and Environmental Microbiology, 45(2), 581-585.

FREITAS, VP., BRIGIDO, BM. 1998. Occurrence of aflatoxins B1, B2, G1, and $\mathrm{G} 2$ in peanuts and their products marketed in the region of Campinas, Brazil in 1995 and 1996. Food Additives and Contaminants, 15(15), 807-811.

GIORNI, P., MAGAN, N., PIETRI, A., BERTUZZI, T., BATTILANI, P. 2007. Studies on Aspergillus section Flavi isolated from maize in northern Italy. International Journal of Food Microbiology, 113(3), 330-338. http://dx.doi.org/10.1016/ j.ijfoodmicro.2006.09.007

GQALENI, N., SMITH, J.E., LACEY, J., ETTINBY, G. 1997. Effects of temperature and water activity, and incubation time on production of aflatoxins and cyclopiazonic acid by an isolate of Aspergillus flavus in surface agar culture Applied and Environmental Microbiology, 63(3), 1048-1053.

HORN, B.W., DORNER, J.W. 1999. Regional differences in production of aflatoxin B1 and cyclopiazonic acid by soil isolates of Aspergillus flavus along a transect within the United States. Applied and Environmental Microbiology, 65(4), 1444-1449

HORN, B.W., GREENE, RL., SOBOLEV, VS., DORNER, JW., POWELL, JH LAYTON, RC. 1996. Association of morphology and mycotoxin production with vegetative compatibility groups in Aspergillus flavus, A. parasiticus, and A. tamari. Mycologia, 88 (4), 574-587.

IARC, 2002.IARC Monographs on the Evaluation of Carcinogenic Risks to Humans.

KLICH, M.A. 2002. Identification of Common Aspergillus Species.CentraalboreeauVoorSchimmelcultures, Utrecht, The Netherlands, $116 \mathrm{p}$ ISBN 90-70-351-46-3

MAENETJE, PW., DUTTON, MF. 2007. The incidence of fungi and mycotoxin in South African barley products. Journal of Environmental Science and Health, 42(2), 229-236.

MARTINS, M.L., MARTINS, H.M. 1999. Natural and in vitro coproduction of cyclopiazonic acid and aflatoxins.Journal of Food Protection, 62(3), 292-294.

MASSEY, T., STEWART, R., DANIELS, J., LIU, L. 1995.Biochemical and molecular aspects of mammalian susceptibility to aflatoxin B1 carcinogenicity.Proceedings of the Society for Experimental Biology and Medicine, 208, 213-227.

NOVAS, M.V., CABRAL, D. 2002. Association of mycotoxin and sclerotia production with compatibility groups in Aspergillus flavus from peanut in Argentina.Plant Disease, 86(3)

$215-219$

http://dx.doi.org/10.1094/PDIS.2002.86.3.215

NUEHRING, L.P., ROWLAND, G.N., HARRISON, L.R., COLE, R.J., DORNER, J.W. 1985. Cyclopiazonic acid mycotoxicosis in the dog.American Journal of Veterinary Research, 46(8), 1670-1676.

PILDAIN, M.B., VAAMONDE, G., CABRAL, D. 2004. Analysis of population structure of Aspergillus flavus from peanut based on vegetative compatibility, geographic origin: mycotoxin and sclerotia production.International Journal of Food Microbiology, 93(1), 31-40. http://dx.doi.org/10.1016/j.ijfoodmicro.2003.10.007

PILDAIN, MB., FRISVAD, JC., VAAMONDE, G., CABRAL, D., VARGA, J. SAMSON, RA. 2008. Two novel aflatoxin-producing Aspergillus species from Argentinean peanuts. International Journal Of Systematic And Evolutionary Microbiology, 58(3), 725-735. http://dx.doi.org/10.1099/ijs.0.65123-0

PERRONE, G., MUle, G., SUSCA, A., BATTIlANI, P., PIETRI, A., LOGRIECO, A. 2006. Ochratoxin A production and AFLP analysis of Aspergilluscarbonarius, Aspergillustubingensis, and Aspergillus nigerstrains isolated from grapes in Italy. Applied and Environmental Microbiology, 72(1), 680-685. http://dx.doi.org/10.1128/AEM.72.1.680-685.2006

PITT, J.I., HOCKING, A.D. 1997. Fungi and Food spoilage.Blackie Academic and Professional. London, 593 p. ISBN: 978-1-4613-7936-2 http://dx.doi.org/10.1007/978-1-4615-6391-4

PROBST, C., NJAPAU, N., COTTY, P.J. 2007. Outbreak of an acute aflatoxicosis in Kenya in 2004: Identification of the causal agent. Applied and Environmental Microbiology, $\quad 73(8), \quad 2762$ 2764.http://dx.doi.org/10.1128/AEM.02370-06

PURCHASE, IFH. 1971. The acute toxicity of the mycotoxincyclopiazonic acid to rats.Toxicology and Applied Pharmacology, 18, 114-123.

RAZZAGHI-ABYANEH, M., SHAMS-GHAHFAROKHI, M., ALLAMEH, A., KAZEROON-SHIRI, A., RANJBAR- BAHADORI, S., MIRZAHOSEINI, H, REZAEE, M.B. 2006. A survey on distribution of Aspergillus Section Flavi in corn field soils in Iran: population patterns based on aflatoxins, cyclopiazonic acid and sclerotia production. Mycopathologia, 161(3), 183-192. http://dx.doi.org/10.1007/s11046-005-0242-8

RIBA, A., BOURAS, N., MOKRANE, S., MATHIEU, F., LEBRIHI, A. SABAOU, N. 2010. Aspergillus section Flavi and aflatoxins in Algerian whea and derived products. Food and Chemical Toxicology, 48(10), 2772-2777. http://dx.doi.org/ 10.1016/j.fct.2010.07.005

ROSTAMI, R, NADDAFI, K, AGHAMOHAMADI, A, NAJAFI SALEH, $\mathrm{H}$, FAZLZADEH DAVIL, M.2009. Survey of peanut fungal contamination and its relationship with ambient conditions in the bazar of zanjan.Journal of Environmental Health Science \& Engineering, 6 (4), 295-300.

SANCHEZ-HERVAS, M., GIL, J.V., BISBAL, F., RAMON, D., MARTINEZ CULEBRAS, P.V. 2008. Mycobiota and mycotoxin producing fungi from cocoa beans.International Journal of Food Microbiology, 125(3), 336 340.http://dx.doi.org/ 10.1016/j.ijfoodmicro.2008.04.021

SCHMIDT-HEYDT, M., RÜFER, C., RAUPP, F., BRUCHMANN, A., PERRONE, G., GEISEN, R. 2011. Influence of light on food relevant fungi with emphasis on ochratoxin producing species.International Journal of Food Microbiology, 145(1), 229-237.

http://dx.doi.org/10.1016/j.ijfoodmicro.2010.12.022

THAMABORIPAT, D., RAMUNSRI, W. APINTANAPONG, M CHUSANATASANA, U. 1992. Effect of sodium chloride, propionic acid and 
ammonium hydroxide on growth of A. flavus on corn and aflatoxin production.ASEAN food journal, 7, 24-29.

TRAN-DINH, N., PITT, JI., CARTER, DA. 1999. Molecular genotype analysis of natural toxigenic and nontoxigenic isolates of Aspergillus flavus and Aspergillus parasiticus.Mycological Research, 103, 1485-1490.

URANO, T., TRUCKSESS, MW., BEAVER, RW., WILSON, DM., DORNER, JW., DOWELL, FE. 1992. Co-occurrence of cyclopiazonic acid and aflatoxins in corn and peanuts. Journal of AOAC International, 75, 838-841.

VAAMONDE, G., PATRIARCA, A., PINTO, V.F., COMERIA, R. DEGROSSI, C. 2003. Variability of aflatoxin and cyclopiazonic acid production by Aspergillus Section Flavi from different substrates in Argentina.International Journal of Food Microbiology, 88 (1), 79-84. http://dx.doi.org/10.1016/S0168$\underline{1605(03) 00101-6}$ 